\title{
Milk, mucus and myths
}

\author{
Ian M Balfour-Lynn
}

Department of Paediatric Respiratory Medicine, Royal Brompton Hospital, London, UK

\section{Correspondence to}

Dr lan M Balfour-Lynn Department of Paediatric Respiratory Medicine, Royal Brompton Hospital, London SW3 6NP, UK; i.balfourlynn@ic.ac.uk

Received 3 July 2018 Accepted 24 July 2018 Published Online First 6 September 2018

\begin{abstract}
'Science must begin with myths, and with the criticism of myths'. Karl Popper, 20th century philosopher
\end{abstract}

\section{INTRODUCTION}

A myth is a widely held but false belief. If it is repeated often by enough people, those who know the truth may start to doubt themselves. Indeed, George Orwell said that myths which are believed in tend to become true. Our department has repeatedly been told by parents that drinking milk increases mucus production from the lungs, and so they stop their child having milk. This is particularly so in patients with conditions associated with excess mucus, for example, cystic fibrosis and primary ciliary dyskinesia, but also includes children with infant wheeze or asthma. Indeed, many people believe milk should be avoided with any respiratory illness, even a common cold.

\section{ORIGIN AND PROPAGATION OF THE MYTH}

It is often written that the belief started with Moses Maimonides, the Jewish spiritual leader and Court Physician in Egypt who died in 1204. In his Treatise on Asthma, written for an asthmatic relative of Saladin the Great, he warns against eating several foods that generate phlegm. ${ }^{1}$ These include fatty food; scalding hot gas-generating foods (eg, black beans, peas); food made from coarse wheat flour and heavy meats. However, while he warns against cheese (especially if very old), his only mention of milk is that all kinds cause 'a stuffing in the head' and it is best to keep away from them. ${ }^{2} \mathrm{He}$ does of course recommend chicken soup that 'assists in the stirring up and ejection of pulmonary phlegm'. Traditional Chinese medical texts have also linked dairy consumption with a humidifying effect and thicker phlegm, ${ }^{3}$ although in reality most of their texts are positive about drinking milk. ${ }^{4}$ The belief is repeated in the influential Dr Spock Baby and Child Care book ${ }^{5}$; first published in 1946, it had sold more than 50 million copies by the time of his death in 1998. Unfortunately, the latest 2011 version still states 'Dairy products may cause more mucus complications and more discomfort with upper respiratory infections...'

\section{WHAT DO THE LAY PUBLIC BELIEVE?}

An Australian study asked 345 random shoppers their views on the health qualities of milk; 51/111 (46\%) of whole milk drinkers, 30/121 (25\%) reduced fat milk drinkers and $12 / 113$ (11\%) soy milk drinkers 'agreed' that milk causes mucus; furthermore, 20\%, $8 \%$ and 5\%, respectively, believed milk caused asthma. ${ }^{6}$ A study in New Zealand of 100 parents of children with chronic asthma were asked what they add or avoid in their child's diet; $36 \%$ had never made changes, but of those who were avoiding something solely due to the asthma, 19/33 (58\%) avoided dairy products, and $10 / 30$ (33\%) had done so previously; just 14\% said this was following medical advice. ${ }^{7}$ In a US study of 330 parents in a paediatric respiratory clinic, 59\% believed drinking milk increased mucus production, 22\% thought it did not, and 20\% were uncertain. $^{8}$ There was no difference according to the child's diagnosis (asthma vs allergies vs cystic fibrosis). Furthermore, when their child was ill, half avoided giving the child milk, despite a fifth of this group not believing milk caused mucus. ${ }^{8}$

\section{DOES IT MATTER IF A CHILD IS NOT GIVEN MILK?}

Milk is the principle source of calcium for children and adults as well as a good source of several vitamins. ${ }^{9}$ Adequate calcium intake is critical for the development of normal bone health and prevention of future osteoporosis. ${ }^{10}$ One study of 50 children who avoided milk showed they were shorter and had reduced bone mineral density compared with 200 milk-drinking children, and only 12\% were taking calcium supplements. ${ }^{10}$ Furthermore, in those avoiding milk, childhood fractures are more common than in the general population. ${ }^{11}$ This issue is particularly important for children with respiratory disease who may require frequent courses of oral corticosteroids. Milk is also an important energy source, for example, Dutch children aged 1-4 years derive about one-fifth of their total energy intake from milk products. ${ }^{12}$ Omitting this important calorie source is particularly deleterious for young children with cystic fibrosis with their increased energy requirements.

\section{WHAT IS THE EVIDENCE?}

\section{Mucus production}

The earliest attempt to obtain real evidence was published in 1948 in California, USA. ${ }^{13}$ The author had asked 200 patients 'does milk make mucus for you?' and 25\% said yes. He then divided 647 patients according to their daily milk consumption $(0-5,6-9,10+$ glasses per week) and found no difference between the groups in terms of whether they complained of mucus in the throat. Nose and throat examinations were carried out on 157 of the subjects and there was no excess mucus noted in those who drank milk versus those who did not. An Australian group challenged 60 adult volunteers with rhinovirus- 2 and over 10 days collected data on symptoms, milk intake and weight of nasal mucus blown into tissues. ${ }^{9}$ Almost half of them believed dairy products were bad for colds and $80 \%$ of those said it was due to milk producing more mucus/phlegm. However, they found no correlation 
between milk/dairy intake and symptoms of upper/lower respiratory tract congestion or weight of nasal secretions produced. They did though find a non-significant increase in looseness of cough with higher dairy/milk intake. Incidentally, this study was partly sponsored by the Australian Dairy Research Council.

A hypothesis for a link has been published but remains unproven. $\beta$-casomorphin-7 ( $\beta$-CM-7) is a protein that is derived from the breakdown of certain types of milk, and this is known to upregulate MUC5AC gene expression and increase mucus secretion. ${ }^{14}$ However, this is in the colon, so can only lead to more mucus in the respiratory tract if intestinal permeability is increased during inflammatory states, thus allowing milk proteins to enter the systemic circulation. ${ }^{14}$ There is no reason though that a viral cold should lead to increased intestinal permeability, so this theory seems unlikely, although may be conceivable in people with cystic fibrosis, with its associated gut inflammation.

\section{Perception of mucus}

The same Australian group studied 169 adults, of whom 41\% believed milk produced mucus. ${ }^{15}{ }^{16}$ Initially, they were asked to describe sensations associated with drinking milk. ${ }^{16}$ The throat was the predominant site affected followed by the nose then mouth. The reported issue was difficulty in swallowing and the perceived thickness of saliva and mucus, but not actually increased amounts of mucus. Those who believed the milk-mucus link reported more respiratory symptoms (most commonly throat clearing and cough) and inevitably drank less milk. The subjects were then given either a flavoured ultra heat treated (UHT) cow's milk drink or a constituted UHT soy milk drink, which was indistinguishable. ${ }^{15}$ Immediately after drinking $300 \mathrm{~mL}$, three variables were significantly increased: 'coating/ lining over the mouth, throat or tongue' (in 39\%); 'need to swallow a lot' (in 31\%) and saliva thicker and harder to swallow than before (in 42\%). However, there was no difference between those having cow's milk versus the soy product suggesting it is not a physiological effect of milk but the sensory characteristics (flavour and mouth feel) that account for the effect. Prior belief in the milk-mucus theory did not affect the outcomes, and there was no impact 4 hours or 24 hours later. It seems the issues were around the perceived physical properties of the mucus rather than the volume produced.

\section{WHY MIGHT MILK MAKE MUCUS FEEL THICKER?}

Milk is an emulsion (defined as a suspension of droplets of one liquid in another) of fat in water, and emulsions mix with saliva. Saliva contains high molecular weight mucin (MUC5B) and mucins are responsible for the viscoelastic properties of saliva. ${ }^{17}$ Furthermore, salivary mucins quickly induce extensive droplet flocculation of the emulsion (formation of aggregates that increase viscosity and increase volume). ${ }^{18}$ This could well affect the sensory perception of milk mixed with saliva, both in terms of its thickness coating the mouth and the after feelwhen small amounts of emulsions remain in the mouth after swallowing. ${ }^{18}$ This may explain why so many people think there is more mucus produced when in fact it is the aggregates of milk emulsion that they aware of lingering in their mouth and throat. The size of lipid droplet aggregates and speed of aggregation varies between individuals, so may also account for why only some people are affected by the sensation. ${ }^{18}$ Another suggestion relates to the calcium ion concentration in milk. Increased extracellular calcium on the surface of respiratory mucosa inhibits hydration of mucin (as has been found in cystic fibrosis) and increases the viscosity of mucus. ${ }^{19}$ However, it is unlikely that drinking milk would lead to an immediate increase of calcium lining the respiratory tract.

\section{Milk and asthma}

Many asthmatics perceive their asthma is worsened by drinking milk, and dairy is often avoided. ${ }^{720}$ While allergy or lactose intolerance is often thought to be the issue, in reality, respiratory symptoms as the sole manifestation of food allergy is uncommon. ${ }^{2122}$ Double-blind milk challenges did not cause bronchoconstriction or respiratory symptoms in two studies of non-milk allergic asthmatic adults, ${ }^{23} 24$ including the $50 \%$ of subjects who believed that milk worsened their asthma. ${ }^{23} \mathrm{~A}$ small study looked at the effect of drinking whole milk, skimmed milk or water on lung function in 11 asthmatic and 10 non-asthmatic adults. ${ }^{25}$ There was no change in airflow parameters; however, interestingly pulmonary diffusing capacity (DLCO) was significantly and progressively lowered by a mean of $21 \%$ over 3 hours in the asthmatics who drank the full fat milk. The authors speculated that it was due to the effect of the milk lipids on gas exchange, but it has been shown that ingesting $1 \mathrm{~g}$ fat (ice cream) per kg body weight had no effect on resting or exercise DLCO. ${ }^{26}$

\section{CONCLUSIONS}

While certainly the texture of milk can make some people feel their mucus and saliva is thicker and harder to swallow, there is no evidence (and indeed evidence to the contrary) that milk leads to excessive mucus secretion. Milk is an important source of calories, calcium and vitamins for children. The milk-mucus myth needs to be rebutted firmly by healthcare workers.

Funding None declared.

Competing interests None declared.

Provenance and peer review Commissioned; externally peer reviewed.

\section{REFERENCES}

1 Rosner F. Moses Maimonides' Treatise on Asthma. J Asthma 1984;21:119-29.

2 Maimonides M. Treatise on Asthma. Translated and edited by S Muntner. Philadelphia, USA: JB Lippincott Co, 1963.

3 Wüthrich B, Schmid A, Walther B, et al. Milk consumption does not lead to mucus production or occurrence of asthma. J Am Coll Nutr 2005;24:547S-55.

4 Dharmananda S. Giving out bad advice? Why natural health care practitioners need to be careful about recommending restricting dairy products. Institute of Traditional Medicine. www.itmonline.org/arts/dairy.htm (accessed 18 Jun 2018).

5 Spock B, Needlman R. Dr Spock's Baby and Child Care. 9th edn. New York, USA: Simon \& Schuster Inc, 2011:421.

6 Bus AE, Worsley A. Consumers' health perceptions of three types of milk: a survey in Australia. Appetite 2003;40:93-100.

7 Dawson KP, Ford RP, Mogridge N. Childhood asthma: what do parents add or avoid in their children's diets? N Z Med J 1990;103:239-40.

8 Lee C, Dozor AJ. Do you believe milk makes mucus? Arch Pediatr Adolesc Med 2004;158:601-3.

9 Pinnock CB, Graham NM, Mylvaganam A, et al. Relationship between milk intake and mucus production in adult volunteers challenged with rhinovirus-2. Am Rev Respir Dis 1990;141:352-6.

10 Black RE, Williams SM, Jones IE, et al. Children who avoid drinking cow milk have low dietary calcium intakes and poor bone health. Am J Clin Nutr 2002;76:675-80.

11 Goulding A, Rockell JE, Black RE, et al. Children who avoid drinking cow's milk are at increased risk for prepubertal bone fractures. J Am Diet Assoc 2004;104:250-3.

12 Wijga AH, Smit HA, Kerkhof M, et al. Association of consumption of products containing milk fat with reduced asthma risk in pre-school children: the PIAMA birth cohort study. Thorax 2003;58:567-72.

13 Moose RM. Does milk "make mucus"? Calif Med 1948;68:31-2.

14 Bartley J, McGlashan SR. Does milk increase mucus production? Med Hypotheses 2010;74:732-4.

15 Pinnock CB, Arney WK. The milk-mucus belief: sensory analysis comparing cow's milk and a soy placebo. Appetite 1993;20:61-70.

16 Arney WK, Pinnock CB. The milk mucus belief: sensations associated with the belief and characteristics of believers. Appetite 1993;20:53-60. 
17 Kupirovič UP, Elmadfa I, Juillerat MA, et al. Effect of saliva on physical food properties in fat texture perception. Crit Rev Food Sci Nutr 2017;57:1061-77.

18 Vingerhoeds MH, Blijdenstein TBJ, Zoet FD, et al. Emulsion flocculation induced by saliva and mucin. Food Hydrocoll 2005;19:915-22.

19 Verdugo P, Aitken M, Langley L, et al. Molecular mechanism of product storage and release in mucin secretion. II. The role of extracellular $\mathrm{Ca}++$. Biorheology 1987;24:625-33.

20 Woods RK, Weiner J, Abramson M, et al. Patients' perceptions of food-induced asthma. Aust N Z J Med 1996;26:504-12.

21 Bock SA, Atkins FM. Patterns of food hypersensitivity during sixteen years of doubleblind, placebo-controlled food challenges. J Pediatr 1990;117:561-7.
22 Jakobsson I, Lindberg T. A prospective study of cow's milk protein intolerance in Swedish infants. Acta Paediatr Scand 1979;68:853-9.

23 Woods RK, Weiner JM, Abramson M, et al. Do dairy products induce bronchoconstriction in adults with asthma? J Allergy Clin Immunol 1998;101:45-50.

24 Nguyen MT. Effect of cow milk on pulmonary function in atopic asthmatic patients. Ann Allergy Asthma Immunol 1997;79:62-4.

25 Haas F, Bishop MC, Salazar-Schicchi J, et al. Effect of milk ingestion on pulmonary function in healthy and asthmatic subjects. J Asthma 1991;28:349-55.

26 Kratina KM, Zauner CW, Siders RA. Effect of hyperlipemia on pulmonary diffusing capacity at rest and during exercise. J Sports Med Phys Fitness 1993;33:258-63. 